\title{
Urban environment and major challenges in sustainable development: Experience from Dhaka City in Bangladesh
}

\author{
Md. Ruhullah Siddiqy
}

Research Officer, Bangladesh Center for Communication Program (BCCP), Mirpur, Dhaka, Bangladesh.

\section{Abstract}

Sustainable development is one of the most discussed and desired issues for the last few decades in Bangladesh and also throughout the world. But due to various challenges it is really tough to prepare and execute a proper plan for achieving sustainable development. The objective of this study is to find out the major challenges that the urban environment has been facing in sustainable development in Dhaka city. The qualitative study was done purposively and data collection methods were 10 Key Informants Interviews (KII) and 10 Focus Group Discussions (FGDs). KII were conducted among university teachers and Government officials as well as FGDs were conducted among city duelers in Dhaka. Urbanization process providing reasonable housing and infrastructure for duelers of all financial gain categories is a nice challenge for capital of Bangladesh town. Lack of swamp, open places, public parks, land with tree cover up causes environmental degradation and also creates aesthetic discomfort is another challenge in urban areas. Surface water is becoming useless because of having extensive pumping of groundwater in capital of Bangladesh. City dwellers didn't follow the environmental rules and pollutes the surface waters with freedom. Impenetrable population with quick urbanization, industrialization and the lack of land coming up with has created major environmental problem to establish sustainable development. In future we need to study on identify the implementation strategy to sustainable development of urban environment.

Keywords: Urban, Environment, Challenges, Sustainable Development, Bangladesh.

\section{Introduction}

Urban environment and sustainable development is instigated each other. Sustainable development in urban depends on sound environment. Urban environment and health is changing by the changing of climate. The world urban population is increasing day by day because of growing urbanization. The world's urban population reached 2.9 billion in 2000 and is expected to rise to 5 billion by 2030.A great rural-to-urban demographic shift taking place throughout the world is fuelling this urban growth.

Urban is the center for culture, science, concept, commerce, productivity, social development and much additional. People are more advance economically. However, many challenges exist in urban to develop or maintain as well as common urban challenges include congestion, lack of funds to provide basic services, a shortage of adequate housing and declining infrastructure. The challenges cities face can be overcome in ways in which permit them to still thrive and grow, while rising resource use and reducing pollution and impoverishment. The future we would like includes cities of opportunities for all, with access to basic services, energy, housing, transportation and more. ${ }^{2}$

United Nation set up the goal about Sustainable Development Goal 11: create cities comprehensive, safe, resilient and sustainable, this is projected to rise to $60 \%$ by 2030 , with almost all the urban growth occurring in low- and middle-income countries. Regardless of size, cities will become the new home of the biggest share of

\section{Practice Points}

- Providing sufficient housing facilities to a large diversity of slum dwellers could be a key challenge as none of the formal land and development agencies give housing to the urban poor.

- Lack of wetland, public parks, open places and land with tree cover up causes environmental dreadful conditions, people deprives from areas for physical activities, and creates artistic uneasiness are different challenges.

- The vehicular emissions area unit caused by two-stroke three wheelers (scooter), poorly maintained old trucks, buses, and other motor vehicles. Bricks kilns around the city conjointly represent to the worsening of air quality.

- The unhygienic situation created by the poor management of solid waste enforces economic prices in the style of health impacts, blocked drainage and artistic suffering.

- Public safety will have to carry on to be compromised at the best population density with rapid urbanization, industrialization and the lack of land use coming up with have created main environmental issues.

many uncountable migrants. Approximately 828 million people live in slums these days and therefore the range keeps rising. ${ }^{2}$ The world's cities occupy just three per cent of the Earth's land, but account for

Correspondence: Md. Ruhullah Siddiqy, Research Officer, Bangladesh Center for Communication Program (BCCP), House: 08, Road: 03, Block: A, Section: 11, Mirpur, Dhaka, Bangladesh. Email: mruhullahs@gmail.com; Ruhullahm96@yahoo.com.

South East Asia Journal of Public Health 2017;7(1):12-16 (C) 2017 Siddiqy., publisher and licensee Public Health Foundation Bangladesh. This is an Open Access article which permits unrestricted non-commercial use, provided the original work is properly cited. 
$60-80 \%$ of energy consumption and seventy five per cent of carbon emissions. ${ }^{2}$ Rapid urbanization is exerting pressure on contemporary water provides, sewage, the living environment, and public health. But the high density of cities will bring potency gains and technological innovation whereas reducing resource and energy consumption. ${ }^{2}$

Among the many urban property challenges inclusion is seen because the most imperative one to tackle. ${ }^{3}$ Like most other property aspects, it cannot be solved on an individual basis during a silo, but it keeps reappearing as a cross-cutting issue. ${ }^{3}$ The need for integration in urban coming up with issues not solely inclusion however urban infrastructure, the solid basis on which property cities area unit engineered. Half the world's population currently lives in urban areas. ${ }^{3}$

Like other developing countries, urbanization in Bangladesh is a growing development, which is steady in nature however fretfully affects urban property in the wake of lacking in smart governance. ${ }^{4}$ Despite urban authorities are involved concerning this issue, they often fail to address the issues attributable to the actual fact of uncontrollable and unpredictable rural to urban migration, and negligence of urban poor's sustainable living and access to basic services. ${ }^{4}$ Virtually the rural impoverishment drawback has been converse to urban areas, particularly in Dhaka town, Bangladesh. ${ }^{4}$ Inadequacy of infrastructural services, basic amenities and environmental goods; environmental degradation; traffic jam and accidents; violence and socioeconomic insecurity area unit the key challenges that are created through speedy urbanization. ${ }^{4}$ The aims of the study were to find out the major challenges that the urban environment has been facing in sustainable development in Dhaka city.

\section{Materials and methods}

The methodology of this qualitative study was done by both primary and secondary data. The target population was 5 university teachers and 5 government officials for Key Informants Interviews which were selected purposively as well as different kinds of city duelers in Dhaka city for 10 FGDs. Two interview checklists in bangle and English was developed to conduct KII and FGDs. The study was conducted during the period of November to December, 2015. In both category the participants who were interested to interview and more than 20 years were inclusion criteria, because of having experience and knowledge on major challenges in sustainable development of urban environment to answer. Data collection was started after getting written informed consent from respondent and interview was conducted by using pretested checklist.

Researcher used convenience/purposive sampling techniques to identify and recruit study participants. A total of 10 FGDs were done among the homogenous group with students (4), day labors (4) and different income groups (2). A total of 10 focus groups were conducted in different locations in Dhaka city (Mirpur -11, Mohammadpur, Dhaka University, Bonani, Gulistan). FGDs setting arrangement was done by Ushape in the classroom and in the home of participant. For each FGD seven participants were confirmed to attend the session. Participants attended a one-time, 90 -minute focus group where they discussed major challenges in sustainable development of urban environment. Each focus group was moderated by a moderator who followed an approved set of checklist. Participants were given an informed consent form and participant's bill of rights to review and sign before participating in the focus group. The 90 -minute focus groups were audio recorded and notes were taken by a note taker. Participants completed a brief form at the conclusion of the focus group to provide important background and demographic information. Transcribed the focus group recordings, coded the transcripts using manually by researcher, and analyzed also done by manually specially researcher contribute on it.

However, the relevant secondary data for this study was collected from published and unpublished sources. The published article or reports were collected by searching internet and unpublished article or reports were collected from project document and university library papers.

\section{Results and Discussion}

Socio-economic characteristics of the respondents Present study was done by $10 \mathrm{KII}$ and 10 FGDs. Among the KII respondents were 5 university teachers and 5 government officials, majority (8) of them were male and few (2) were female. The age of the respondent were $>35$, educational qualification were completed masters from reputed university and their income level were BDT $>30,000$. On the other hand, among the 10 FGDs were done with students (4), day labors (4) and different income groups (2). The study show that majority of the FGDs respondents age were $>20$, educational qualification were completed SSC and their family income were BDT $>21,000$.

\section{Qualitative findings (KII \& FGDS)}

Urbanization have been using as a strategically method for development. But still currently there are unit several challenges in capital of Bangladesh for environmental property development for folks of all financial gain categories. For make living comfortable by maintain a distinctive character of residential areas and different kinds of challenges (Example- earthquakes, population, climate change, shortage of land) are increasing for urban development.

\section{Housing and Infrastructure}

Rehabilitation for the urban poor's and housing are the major challenges in cities of developing country. One of the respondents (KII) opined:

"There was no urban planning from the starting of capital of Bangladesh town. Many buildings were in risk of earthquake as a result of capital of Bangladesh town is the most vulnerable position among the South-Asian countries. On the other hand, most of the building was billed with terribly short distance, for this reason adequate fresh air is tough in the capital of Bangladesh town."

In urban areas low income people were leaving in slum. There were inefficient management of slums and squatter settlements were also a major challenge for urban sustainable development. Slums need to be managed to form them get pleasure from and contribute to the dynamic urban economy. One of the FGD 
participants told:

"Providing sufficient housing facilities to a large diversity of slum dwellers could be a key challenge as none of the formal land and development agencies give housing to the urban poor. They always face political, environmental and health dilemma."

City slum dwellers should be enabled to complement their main sources of financial gain to overcome impoverishment. Slums are a partial outcome of urbanization, explosion of slums needs to be dispirited. In another study shows that rehabilitation of the urban poor and housing are the major challenges in cities of developing country. ${ }^{1}$ Similarly, in Dhaka city of Bangladesh, almost $34 \%$ of the city's 13 million residents live in 5,000 slum and squatter settlements. ${ }^{10}$ The growth of the cities both in terms of areas and population has consistently been faster than the growth of infrastructural provisions and services in Dhaka. ${ }^{1}$ As a result, a large section of the urban population does not have access to basic infrastructure services. ${ }^{1}$ The services include housing, water and sanitation, drainage, roads, gas, and electricity supply. ${ }^{1}$ Insufficient and unhealthy housing in the cities, particularly in Dhaka, is the major infrastructural problem in Bangladesh. ${ }^{11}$ The rapid growth of population and low affordability of the people have resulted in poor housing situations, such as slums and squatters. ${ }^{12}$ The availability of land for housing is limited, and hence the costs are gradually soaring. Moreover, nearly, two-third of the urban population is unable to acquire and within reasonable distance from their work place. ${ }^{13}$ Besides housing, the basic utility services like water, electricity, and gas are very essential in everyday life. ${ }^{1}$

\section{Wetland, open spaces and public parks}

Lack of wetland, public parks, open places and land with tree cover up causes environmental dreadful conditions, people deprives from areas for physical activities, and creates artistic uneasiness are different challenges. FGD participants told:

"City dwellers can't move freely at the leisure time. For this reason mental improvement of child and plenty of physical issues are unit increasing day by day."

Similarly, of those who hadn't visited their nearest park, the reasons provided for not doing so varied. The greatest concern was for environmental issues, mentioned by $41 \%$ of respondents who did not visit their nearest park, followed by a lack of security $(35 \%)$ and a lack of cleanliness $(34 \%) .{ }^{14}$ In another study depicted that within the Dhaka City Corporation area, it is not only Osmani Udyan alone which has been grabbed by different quarters, other parks also have come under threat of encroachment; the government itself several times built establishment in Osmany Udyan ground ignoring the need of a park for a city life and for ecosystem; like the parks of Dhaka, trees have been chopped down on silly grounds, sometimes to widen the roads, sometimes to straighten the roads or sometimes to build new buildings and always behind this the authority is in collusion with political elites. ${ }^{15}$

\section{Water supply and Groundwater}

Pumping from groundwater in capital of Bangladesh has brutally worn out. Surface water as a viable water source is challenging as it is usually contaminated by unprocessed environmental pollution and industrial waste. In urban areas, the long term aim of the concerned authority should be extend the general public sewage system as shortly as doable. Many new stapes need to be start for predictable future development of different solutions is named for. One of the FGD participants told:

"In Dhaka town water downside is one of the largest issues. Generally water provide is extremely restricted in an exceedingly day that is extremely touch to fulfill dweller's wants. Sometimes this water is not appropriate for drinking as a result of having abundant mud, which is not doable to pure when boiling."

Industrial waste is now big issues and challenges to protect surface water and human health. In Dhaka city there were lack of enforcement of ecological system and trade pollutes the surface waters with freedom. The burning issue is to reduce pollution of surface water, both on-the-spot and centralized action of industrial effluents is needed.

The similar study shows that the urban authorities are unable to provide these services to all urban people, particularly to the urban poor. ${ }^{1}$ Only $40 \%$ of urban populations have access to hygienic sanitation. ${ }^{13}$ Water supply system is also insufficient for which the quality and quantity of water are always unsatisfactory to the dwellers; the garbage disposal system in the city is yet to be completely satisfactory too; few areas of the city are going to be managed by sustainable garbage disposal system after government and non-government organizations and community development. ${ }^{1}$ Nonetheless, $35.1 \%$ of them do not have any garbage collection system. In addition, a study by Enayetullah (1995) ${ }^{17}$ reports that the Dhaka city corporation area generates 3,000-3,500 metric tons of municipal solid waste daily, of which $42 \%$ is collected by the management authorities, but rest of them remains on roads, open drains, and low-lying areas.

Equally competing with this is the ever shortage of Water Supply and Sewerage system of this city. The water supply system; an extensive production system of collecting water from groundwater reserve $(90 \%)$, meets only $50 \%$ of the total demand. ${ }^{18}$ From this study, in the dry season, water shortages become so acute that the Government had to deploy the army to prevent water pilfering in Dhaka.

\section{Urban Vehicles}

Quality of air in Dhaka has been one of the worst among several developing cities of the globe. There are 2 major sources of air pollution that embrace industrial emissions and another is conveyance emissions. Brick kilns, fertilizers factories, spinning mills, tanneries, garments, bread and biscuit factories, chemical and pharmaceutical industries, metal workshops etc were included in industrial sources. The vehicular emissions area unit caused by two-stroke three wheelers (scooter), poorly maintained old trucks, buses, and other motor vehicles. Bricks kilns around the city conjointly represent to the worsening of air quality. Recent banned two-stroke vehicles in 
capital of Bangladesh remarkably contributed to improvement of environmental quality.

One of the respondents (KII) opined:

"The traffic-jam in Dhaka town is currently major challenge as a result of having unplanned urbanization. There are heaps of reasons for traffic-jam: additional urban duelers, no planning street, unskilled drivers, lack of awareness and many slow vehicles."

Another study shows that faulty traffic signaling systems, inadequate manpower, narrow road spaces and overtaking tendency of drivers create pro-longed traffic congestions; due to traffic jam a substantial portion of working hours have to be left on streets which indirectly put adverse impact on economy; it causes serious air pollution and noise pollution and thus worsens the overall environmental condition. ${ }^{19}$

From this study, in Dhaka city most of the vehicles were reparable exceeds standards reducing air pollution. Mobile source will remain the main concern for production control in urban areas and diesel run vehicles were also an explicit concern in capital of Bangladesh. Measures aimed at scheming the age of vehicles got to be assessed, as well as further promotion of economical convey is to be needed.

Another study depicted that rickshaws and other NMT account for $50 \%$ or more of the overall traffic flow on roads; after pedestrians, the rickshaw is the most preferred mode of transport in Dhaka. About $60 \%$ of trips are on foot while almost half of the remaining trips are on non-motorized vehicle; other available modes are so crowded that the dwellers are not able to use them anyway and across all modes of transport average trip lengths for NMT are about $1.3 \mathrm{~km}$ (36 minutes) and for motorized transport are $9 \mathrm{~km}$ (45 minutes). ${ }^{20}$ In developed countries, between 2 to 8.5 percent of accidents are directly caused by faulty vehicles. ${ }^{21}$

\section{Management of Solid Waste}

The management of solid waste in urban areas remains a major challenge. The population of more than five million people living within the area covered by DCC produces about 3,500 tons of solid waste daily, of which only $42 \%$ is collected and disposed of at an open unlined landfill site. ${ }^{4}$ The trend of urban population growth has outstripped the capacity of city governments to provide effective and efficient delivery of conservancy services and as a result, nearly $50 \%$ of the daily generated garbage remains uncollected in the cities of Bangladesh. ${ }^{5}$ A 'gap' exists between the daily generation and the collection of solid waste, which leaves urban administration vulnerable to citizens' complaints. Weak institutional incentives and capacity have been at the base of the dysfunctional in urban service deliver and the challenge will be even greater by 2020 when the demand for removal of solids waste may raise to 50,000 tons/day from the present 10,000 tons/day. ${ }^{6}$

From FGD findings one of the participants said:

"The unhygienic situation created by the poor management of solid waste enforces economic prices in the style of health impacts, blocked drainage and artistic suffering."

\section{Rapid Business Pace}

The rapid urbanization of the city since its emergence as the capital of an independent state is due mainly to massive migration of rural population; significant portions of the city dwellers are settled mostly in slums and squatter settlements and are living below the poverty lines as the rapid urban growth of the city is not commensurate with its overall development. ${ }^{21}$ Dhaka is the central from geographical location and all the business opportunity available in the city. From the beginning of Dhaka city urbanization process and business prospect is growing rapidly side by side.

According to FGD participant:

"The quick pace of urbanization continues as business area unit increasing their procedures adding up together to the difficulty of the already comprehensive transport capacities of the cities. The City Corporation has to take stapes the growing problems with scarce assets."

Study findings shows that public safety will have to carry on to be compromised at the best population density with rapid urbanization, industrialization and the lack of land use coming up with have created main environmental issues that contribute to increasing disaster risks, particularly in urban areas. In this context, it is significant to sustain urban development.

On the same area another study reveals that many of the suggestions set out in the plan appear unrealistic or impractical; for example, the shift from a monocentric city to a polycentric city will depend upon a totally new metropolitan road pattern and mass transit system and apart from the first section of the eastern artery, the Progati Sarani, which provides a new link from the CBD to the Airport, none of these infrastructure projects has been implemented. ${ }^{23}$

Operational Challenges of Conservancy Department

The conservancy department of Dhaka faces operational challenges such as the lack/misuse of resources, corruption, political interference, political relationships, lack of interdepartmental management, and lack of people awareness. One of the KII respondents told:

"For acceptable concentrated effort of town area unites at least 2 sweepers were needed per thousand populations. In addition to this, Dhaka City Corporation delivers services to their purchasers with insufficient men."

Dhaka has been divided into 10 administrative zones where a conservancy officer runs the conservancy service of a zone and all wards receive regular conservancy services; for this Dhaka does not have any non-conservacy ward like other municipalties as well as all service users pay $2 \%$ conservancy tax with their annual household taxes. ${ }^{1}$ The corporation employs around 7500 sweepers to sweep roads/lanes and clean drains. ${ }^{24} \& 16$ Formally, the cleaners (mainly the female sweepers) of Dhaka 
are supposed to sweep the roads and lanes daily in three shifts: morning, day, and night within the officially assigned duty hours between 6 am to $2 \mathrm{pm}$, and $7 \mathrm{pm}$ to $3 \mathrm{am}^{26}$ Now the different kinds of problems of conservancy department are challenges for urban sustainable development.

\section{Conclusion}

There are lots of challenges in urban environment of Bangladesh have to face to attain sustainable development. Major challenges in urban sector were housing and infrastructure, industrialization, lack of land, water supply and waste management. Government of Bangladesh should address these problems properly and need to take proper plan to overcome these challenges. Government need to step to aware the people and compliance with the law. It is tough to face all of the challenges. But the government should prioritize the challenges and need to resolve these challenges. We should be strategic and stay focused to overcome these challenges. In every stages of development we have to face new challenges. But it is natural and we should take a proper plan to face these challenges. In future we need to study on identify the implementation strategy to sustainable development of urban environment.

\section{Competing interest}

The authors declare that they have no competing interests.

\section{References}

1. Abdullah M, Das SK, Tatsuo O. Urbanization and sustainability challenges in Dhaka city, Bangladesh.

www.academia.edu/10309544/

Urbaniza-

tion and sustainability challenges in Dhaka ci ty Bangladesh (accessed June 2017)

2. United Nation. Sustainable Development Goals. http://www.un.org/sustainabledevelopment/ cities/ (accessed June 2017)

3. Kaarin T. Challenges and way forward in the urban sector. Sustainable Development in the $21^{\text {st }}$ century (SD21). Report for the UN Department of Economic and Social Affairs. New York: UNDESA, 2012.

4. Rana MP. Urbanization and sustainability: challenges and strategies for sustainable urban development in Bangladesh. J Env Dev Sust 2011; 13(1): 237-256.

5. Bhuiyan SH. A crisis in governance: Urban solid waste management in Bangladesh. Habitat Int 2010; 34 (1): 125-33

6. World Bank. Bangladesh 2020: A long-run perspective study. Dhaka: University Press Limited, 2003.

7. Narain JP. The challenge of health and environment: Profiling risks \& strategic priorities for now \& the future. Indian J Med Res 2012; 136(2):185-91.
8. World Commission on Environment and Development (WCED). Our Common Future. Oxford: OUP, 1987.

9. Asaduzzaman M, Hye HA. When both market and state fail: the crisis of solid waste management in urban Bangladesh. Dhaka: Centre for Policy Dialogue and University Press, 1998.

10. Islam N. Slums of Urban Bangladesh: Mapping and Census, 2005. MEASURE Evaluation https://www.measureevaluation.org/resources/ publications/tr-06-35 (accessed 2006)

11. Uddin MN, Jones EM. Sanitation: the crisis of the urban poor. http:// $\underline{\text { re- }}$ searchonline.lshtm ac.uk/2551412/1/2015 WP67 Inequalities in human wellbeing in the urban Ga (accessed June 2017)

12. Islam N. Settlements of the urban poor in Bangladesh. US Bull Urb Dev 2000; 38:2-4.

13. Work for a Better Bangladesh. Parks and playgrounds in Dhaka: taking stock and moving forward. Health Bridge funding for this study. Dhaka: WBB Trust, 2015.

14. Islam BMS. Reduction of open space in Urban Planning: A case study of Osmani Udyan. [thesis]. Dhaka: BRAC University, 2010.

15. Enayetullah I. A study of solid waste management for environmental improvement of Dhaka city. An unpublished Masters of Urban and Regional Planning. [Thesis]. Dhaka: BUET, 1995.

16. Mahmud K, Gope K, Chowdhury SMR. Possible Causes \& Solutions of Traffic Jam and Their Impact on the Economy of Dhaka City. J Manag Sust 2012; 2(2):1-25.

17. Mannan SM, Karim MM. Current State of the Mobility of the Urban Dwellers in Greater Dhaka. Paper for Presentation for 94th Annual Conference and Exhibition of Air and Waste Management Association, June 24-28, 2001, Orlando, Florida, USA.

18. Khan SM. Traffic Flow Interruptions in Dhaka City: Is Smooth Traffic Flow Possible? $J$ Presidency Uni 2013;2(2):46-54.

19. Hossain S. Rapid urban growth and poverty in Dhaka City. Ban e-J Socio 2008;5(1).

20. Joarder S. Sustainable Development and the Urban Environment in Developing Countries: the experience of Dhaka. https:// www.scribd.com/document/259548052/

Sustainable-Development-and-the-Urban-

Environment-in-Developing-Countries-theexperience-of-Dhaka (accessed June 2017)

21. Bhuiyan SH. A crisis in governance: Urban solid waste management in Bangladesh. Habitat Int 2010;34:125-33 